\title{
10. Hierarchy and Equality in Fijian Kindergartens
}

\author{
Karen J. Brison
}

\section{Introduction}

In 1983, when I was a graduate student, Donald Tuzin changed the course of my career by writing a National Science Foundation grant, part of which funded my dissertation research among the Kwanga of the East Sepik Province of Papua New Guinea. Tuzin proposed an ambitious comparative study of four neighbouring Sepik cultures. He argued that an important part of socialisation came through experience with other children. Among the Ilahita Arapesh, boys tell each other fearsome stories about cult spirits, and even though they later learn that these stories are just lies designed to frighten women and children, they continue as adults to have frightening dreams of cult spirits (Tuzin 1987). The same belief system, Tuzin argued, might have quite different personal meaning for individuals depending on how children were positioned in society and on the nature of their early experiences with these cultural beliefs. Even though the Ilahita Arapesh and three neighbouring groups had very similar male initiation cults, he continued, the personal meanings of these beliefs for individuals could be different in the four groups if children's early exposure to the belief systems differed.

My PNG research did not end up focusing on children's peer groups, but I was intrigued by Tuzin's ideas and realised, when I later put together courses on the anthropology of childhood, religion and other topics, that he was ahead of his time in suggesting that children internalised many of their assumptions about self and culture through interacting with other children. Kulick (1997), for instance, argues that children of Gapun village in the East Sepik lead the shift away from bilingualism to monolingualism in Tok Pisin - one of the two PNG lingua franca. Adults want their children to be bilingual but child caretakers generally use Tok Pisin with younger children in an effort to enhance their own authority by drawing on the associations of Tok Pisin with reason and wisdom. More generally, Corsaro (1997, 2003), Harris (1999), Tannen (1990) and many others all suggest that children are not directly socialised by adults. Instead, children understand from an early age that they are children, and they form their ideas about appropriate behaviour and values by internalising routines and assumptions in a world of peers. One peer culture gives way to other peer 
cultures as children grow up, but our understandings of self and society are acquired through this succession of peer cultures rather than through adult instruction.

In 1997, when I began new fieldwork in Fiji, my research agenda was shaped by Tuzin's ideas about peer socialisation. I argued that Fijian childrenrelegated to the bottom of the status hierarchy in a culture that ranks everyone by age, gender, lineage membership and other criteria-internalise many of their assumptions about self and society through playing with other children, because they are excluded from many adult activities and spend much of their time in the company of other children while higher-status adults pursue important communal activities. In this chapter, I compare the ways urban and rural Fijian children enact and interpret hierarchy and equality in their play in order to revisit another of Tuzin's insights: that the same cultural system can have very different meanings depending on the ways that children experience those beliefs.

In Fiji, as in neighbouring Samoa (Ochs 1988) and Tonga (Morton 1996), lowranking people must obey and accommodate those further up who are thought to be wiser and to have a greater capacity to understand and act for the good of society. This principle structures interactions from the way adults talk to infants (Ochs 1988) and the fostering of children to meet the needs of adults, to interactions among siblings where the older siblings are expected to take care of younger siblings, who owe deference and obedience in return. In rural villages, a large part of children's experience of hierarchy comes from spending their lives in mixed-age peer groups where they both obey older children and discipline younger children. I shall argue that children's experience of the cultural principle of hierarchy is quite different in urban areas where they spend much less time in mixed-age groups and a great deal more time in the same-age cohorts favoured by educational systems all over the world (Anderson-Levitt 2003). As a result, they interact with a large group of unfamiliar equals - their classmates - and experience hierarchy as a binary opposition between those with authority, the teachers, and those without, the children. In contrast, rural children are part of a world of kin where no-one is equal and differences in rank are gradual and continuous, starting with the child one month one's senior and extending through to the oldest grandfather.

I suggest that the new experiential world of children is changing the way they internalise understandings of self and society and that these differences are reflected and reinforced in play. Rural children experiment simultaneously with being higher and lower in rank in their mixed-age play groups. Urban children, on the other hand, develop strategies for negotiating their way through a world of equals by strategically defining in-groups and out-groups. They experience themselves as being powerless in the face of powerful adults and play a variety 
of games, such as pretending to be monsters, superheroes and other powerful figures, which allow them both to defy authority and to play at being powerful. Such play is similar to that of children in American and European schools, who are faced with a similar situation of being powerless in a world where they will some day be required to be autonomous adults (Corsaro 2003; Jones 2003; Paley 1986). These games reflect concerns and assumptions of self and society fundamentally different from those in the games of rural children, who always see themselves as 'dividuals' embedded in a community, neither powerless now nor destined to be powerful in adulthood, but always high with respect to some and low with respect to others. Moreover, the experience of rural children in shifting their behaviour from context to context-depending on the age of the other children present - causes them always to think of themselves as playing roles in a larger communal structure rather than as individuals whose unique characteristics determine their relationships.

\section{Hierarchy in the World of Rural Children}

Cultural assumptions about hierarchy and the correct relationship between adults and children were largely similar in rural and urban areas, but the experience of children was fundamentally different. Morton (1996) and Ochs (1988) note strong cultural assumptions in Tonga and Samoa that children are born foolish, wilful and selfish and only gradually develop the capacities to reason, to think of others and of communal good, and to curb their impulses. On the one hand, these assumptions lead to authoritarian parenting strategies; since children have a limited capacity to reason and are naturally naughty, adults must be firm, in control and often need to use a bit of corporal punishment to impress upon children the right way to behave. On the other hand, since adults are of high status, they should not spend their lives accommodating children's needs; instead, adults are often distant, assigning much of the work of caretaking to older children. Children should not be underfoot, distracting adults from important communal work, and they must accommodate the needs of adults by, for instance, doing manual labour. These cultural assumptions shaped the behaviour of rural Fijian parents (Brison 1999) and also urban kindergarten teachers (see below), but the experiential worlds of urban and rural children were rather different because urban children spent more time in schools and less time in neighbourhood and extended kin groups.

In the rural area of Rakiraki, four and five-year-olds lived almost exclusively in a world of kin. I kept track of 13 children between three and five years old over a period of several days in 1997, noting what they were doing and who they were with at random intervals. They were almost always found with members of their own families, most often in the company of their own siblings 
or closely related children. Rakiraki children in general were discouraged from wandering far from their own homes and from entering the compounds of other lineages, unless visiting relatives from those lineages. In 2003, a small kindergarten opened in the compound of the lineage with which I lived. Visits to the kindergarten, however, revealed that it was frequented primarily by children who were closely related to each other and knew each other already, since there was another kindergarten at the other end of the village serving children there. Children in the kindergarten also ranged in age from three to six since parents liked to send siblings to school together.

One consequence of these patterns was that children were almost always part of a kin hierarchy since they were seldom away from siblings and cousins. At home, there were generally few enough children in any one lineage that all the children - from two-year-olds to teenagers - often ended up playing together. In such a world, children experimented with being both a higher status and a lower status person (Brison 1999; see also Morton 1996), and the lived experience of hierarchy was one of a continual gradation of closely connected individuals. Children's focus on relative rank was apparent, for example, in one interaction I observed involving two four-year-olds, Mere and Tukana, who lived near each other and often played together; Minroti, a six-year-old boy; and two threeyear-olds, Merioni and my son, Jeffrey (Brison 1999). Mere and Tukana were pretending to be soldiers until they saw Merioni and Jeffrey climb on to the foundation of a new addition to a house. The two older children showed their internalisation of age hierarchy when they immediately headed over to get the two younger children off the foundation, saying, 'Jeffrey, forbidden, you are a baby', and then chasing Merioni off, counting as they had heard adults doing: 'Quickly, four, five you have to be missing from here!' The children were then joined by the slightly older Minroti who now assumed the authoritative role, telling Tukana not to hit smaller children when Tukana tried to frighten Merioni off the foundation. On other occasions, I saw Minroti, who was the youngest in his sibling set, being ordered around by his older siblings. On these and other occasions, rural children experienced hierarchy as a continuous gradation. Children continually moved from being high to being low as the composition of groups changed; they lived in a world where no-one was equal but where there was no clear dichotomy between power and powerlessness either. They also took seriously their responsibilities to supervise younger children and to defer to older children.

I suggest here that one consequence of this situation was a relative absence of 'monster' play or other kinds of play that involved working through relationships with remote, powerful others. Corsaro (2003) observed monster play in both American and Italian preschools. One child would assume the role of monster, and the others would first sneak up on the monster and then run away shrieking 
in mock terror. Jones (2003), Lanclos (2003), Paley (1986) and others have argued that such play helps children who are sociologically small and weak but know they will grow up to be independent adults experiment with power. They work through fears of a dangerous outer world in safe ways by 'killing monsters' and, conversely, they assume powerful monster or superhero roles to gain the experience of being powerful and venting aggression in safe ways.

Fantasies of power were not common in rural Rakiraki children's play. Rakiraki boys of ten or older did sometimes imitate superheroes. I once watched two boys both pretending to be Jean-Claude Van Damme (Brison 2007). But there was no clear villain nor was power over others much emphasised; instead, the boys imitated a scene from a movie that had recently been shown in the community hall in which Van Damme struggled to prevent a jeep from pulling away. Each boy took the role of the jeep driver making engine noises so the hero-villain opposition from the original was lost. Relative power was also not emphasised in a game of house I witnessed played by four small children (Brison 2007). 'Mum' and 'Dad' were significantly absent from this game with each child taking the role of an adult visiting with friends.

In short, I suggest that for Rakiraki children there is no clear dichotomy between adult power and childhood powerlessness in a world where children are sometimes high and other times low in peer groups. Like the perfect 'sociocentric' self described by Becker (1995) and Mead (2001), rural children always think of themselves as playing a role vis-a-vis others, in a ranked community, alternately taking responsibility for lower-ranking people and deferring to higher-ranking people. Children are constantly reminded when the composition of groups changes that expectations of them are linked less to their unique personalities than to the position they occupy in the group of the moment.

\section{Hierarchy in Fijian Kindergartens}

Suva kindergartens were shaped by the same assumptions about rank that moulded rural parenting. But the experience of urban kindergarten children was much different because classrooms contained a large cohort of unrelated children of the same age who were all relatively powerless in contrast with teachers.

Suva kindergarten teachers clearly had beliefs about the need for wise adults to have firm authority over foolish children. Corporal punishment was not allowed in Fijian schools, but most teachers felt that using corporal punishment would have been helpful since children lacked the capacity to reason so timeouts had limited impact. Assumptions about rank also moulded teaching strategies. Teachers insisted that learning was a matter of listening to adults; 
if you did not understand it was because you had not listened. One teacher, for instance, routinely contrasted 'clever' children who listened obediently with 'naughty' children who failed to pay attention on the implicit assumption that learning was a process of allowing your foolish mind to be guided by the higher wisdom of an adult. One outcome of these ideas was what one teacher called 'parrot teaching' - a popular strategy where the teacher would tell the children a piece of information and then have them repeat it. For instance, when one teacher read her class the story of a sheep, Wooly, she read each line and then repeated it back omitting some key word: 'On this farm there was a sheep named Wooly. On this farm there was a sheep named___?', waiting for the children to obediently repeat back the information after every sentence. When teachers asked more open-ended questions, they often had a single correct answer in mind. One teacher, for example, told me that her goal was to make her kindergarten children independent. This meant, she continued, that they should learn in kindergarten what they were expected to do so that they could just do that without being told. She assumed there was a correct way to think about things and that being independent involved grasping that correct way so one could do what the teacher wanted without being told. For example, teachers often reminded children that near the end of the school year, or even midway through, they should not need to be told to sit quietly, sweep floors, or wipe tables; they should already know that these things needed to be done and do them on their own initiative. Similarly, when another teacher told me that her main goal was to make children confident, she elaborated by explaining that confidence involved knowing the right thing to do in each situation so that one could feel sure one was behaving correctly.

Equally evident was the influence of cultural assumptions about the importance of children accommodating adults. For example, many kindergartens comprised large groups of 30 to 50 children rather loosely supervised by two or three adults. Teachers often left children to sort out their own problems, only occasionally intervening, and to play as they chose while teachers talked with each other or to visiting parents and so on.

While cultural assumptions moulding interaction between adults and children were similar in rural and urban areas, children's experience of hierarchy was, in practice, different. Rural children experienced hierarchy as a continuous gradation where one was sometimes high and other times low and often not around adults at all. But urban kindergarten children were unambiguously low in a school hierarchy that involved a clear binary division between teachers and children. The home world of many urban children also had this character since urban children were much more likely to be kept within their own house's compound than allowed to play with mixed-age neighbourhood groups of children. For example, the two children in the household I lived with in Suva 
were generally in their own house, watching TV or playing together. There was always an adult present, and the older child was never encouraged to supervise the younger child. Under these conditions, children experienced their social world as consisting of a large cohort of relatively powerless equals who stood in opposition to powerful adults. These conditions encouraged two kinds of play that I seldom saw in Rakiraki - that is, routines for controlling peers by defining in-groups and out-groups, and fantasies involving either exercising arbitrary and often negative power over others or acting out against oppressive authority figures.

Corsaro (2003), Jones (2003), Lanclos (2003), Paley (1986) and others observed a great deal of 'power' play among American and European children. One child assumed an exaggerated authority role, and the others would resist or act out. Children experimented both with getting out their aggression against authority figures and with being powerful in a world where they were generally powerless. Jones (2003) argues that such play helps children vent frustrations in safe ways and also alleviates anxieties about powerlessness by assuming powerful fantasy roles. In short, this kind of play is typical of children who feel powerless in society and will be expected at some time to become autonomous.

Playing with power was frequent in Suva's urban kindergartens. An obvious example of this kind of play was the game of pretending to be a teacher, which I observed in two or three preschools. In one small preschool, for instance, the teacher often threatened misbehaving children with a yellow plastic belt, which she referred to as 'my yellow friend'. One day when she was in another room, preparing for lunch, one boy, Christopher, who was frequently threatened with the 'yellow friend', grabbed the belt and started pretending to be the teacher, wielding his authority over the anthropologist (KB), and his classmates Ryan, Richard, Ethan and Aaron. From my notes:

Christopher is holding the yellow belt, and says 'Enough you two! This yellow flend!' hitting at KB. Ryan grabs at the yellow belt. Richard looks at KB and says, 'Lasu Lasu' (liar liar) for no apparent reason, and two others take up the chorus. They all run to Aaron who is giving away lollypops, usually doled out by the teacher as rewards...Ethan now grabs possession of the belt and hits Richard while Christopher yells at Ethan (a chubby child), 'Fatty booma!' Ethan then hits the floor with the belt, and Christopher gets up on the table and walks right over the colouring books of a group of girls. The teacher now comes back in and orders them all into the other room. Aaron comes running in with a blue ruler the teacher sometimes uses to threaten children, and the teacher says 'Oh my blue friend! Who wants my blue friend?' 
On this occasion, the children, in a rare moment of freedom from adult supervision, 'cut loose', doing all sorts of forbidden things such as calling the ethnographer a liar, walking on tables and on colouring books, insulting others for being fat and so on. They also assume autocratic adult roles, threatening each other gleefully with the teacher's 'yellow friend' and 'blue friend', and doling out forbidden treats. These behaviours all reflect a world with a clear dichotomous hierarchy. Rural children are often unsupervised; they are often in situations where they must guide and direct younger children; they do not act out against authority but instead take on responsible adult roles in the presence of younger children. Urban kindergarten children, in contrast, are used to being controlled by adults and are seldom put in charge of other children. They experience themselves as powerless in the face of teachers; when given the chance they play gleefully at being autocratic authority figures and at acting out against such figures in the safe context of play with peers who will not punish them.

Similar themes were evident in another urban kindergarten, when a group of boys started playing teacher and students after the teacher had left the room to go talk on the telephone. That morning, during story time, the teacher had threatened to swat a couple of the boys over the head with her book for talking and moving around while she was reading. When she left the room, one of the boys in the class sat in her chair and started imitating her while his friends lined up on the floor in front of him, assuming the role of children in the class. From my notes:

Epeli sits on the teacher's chair holding a book while a group of five boys sit on the mat facing him, where the class would usually sit. One of the boys in the 'class', says 'Teacher, teacher somebody play here.' Another boy in the 'class' keeps pointing to the books saying, 'Monkey, monkey there!' Epeli waves his arms and says, 'Move back! Move back!' as the teacher often does with her class. Epeli slaps one of the boys on the head with the book, and they all move back grinning. The boys grin and move forward toward the teacher and he grabs the teacher's ruler and threatens them...Epeli says, 'Listen to Teacher! Hear that story.' The boys in the class take turns getting up and standing in front of Teacher Epeli and saying, 'Teacher', and being pushed back down. Epeli now starts pushing his chair backward, and the boys follow him sliding forward on their bottoms. Epeli swats one of them on the head and then starts sliding his chair forward, and they all grin and start crawling quickly away from him. Epeli gets up and walks away, and three of the boys race for his chair and then turn giggling and run away when he comes back. One of the boys gets up and hands the book to Epeli and says, 'Teacher, a book', and then starts dancing around in front of Epeli 
daring him to hit him. Epeli grabs the teacher's ruler and starts chasing the boy, and then picks up the books and starts chasing his 'class' with it. The boys run away giggling.

Again, the boys here are having fun assuming the role of arbitrary and abusive power and then acting out against an authority figure, reflecting the concerns of children who feel powerless, and experimenting both with defying authority and with assuming power.

Experimenting with power was also evident in another sequence in the same preschool where Melea, Sera and Amy were playing house. Rakiraki girls playing house had imitated friends going to visit each other. There were no parents and no apparent power differences in their game. In the urban kindergarten, in contrast, Melea became 'Mum', ordering the other children around and wielding a ruler against misbehaving boys, who baited her. From my notes:

Sera says to Melea, 'Mom, Mom the baby is crying.' Melea and Amy ignore her. Two boys come into the house corner, and Melea swats them with the teacher's ruler. Melea points her ruler and says to Sera, 'Make the baby a drink.' Sera feeds the 'babies' (three teddy bears) who are 'sleeping' on the lower of two tables stacked one on top of the other. Sera then brings Melea a cup, and she pretends to drink tea and eat a biscuit. Melea notices three boys have gone under the table, disturbing the babies, and swats one of them with her ruler telling them to get out. The boy looks surprised and then calls her name 'Melea, Melea' and purposefully reaches in to disturb the sleeping babies. He runs away as she starts hitting him with the ruler. He laughs, and she yells at him to stay out of the house. The three boys sneak toward the house chanting, 'Melea, Melea', and she chases them with a ruler until she corners one of them and hits him until he starts crying.

Here, house play became a game of power. The friends visiting each others' houses in the rural game are replaced with an authoritarian mother who orders her children to feed the babies and to make tea and then punishes children for misbehaving. The children experiment both with being an aggressive, powerful, adult authority figure (the Mum) and with acting out against such an authority in the (relatively) safe context of play with other children.

Children's superhero play also had a different character than that of the rural children. The rural boys each emulated Van Damme with no clear opposition between hero and villain. Urban kindergarten boys, on the other hand, clearly focused on wielding power over others. From my notes:

Christopher is sitting on the first floor of the playhouse with Peter. They have toy airplanes. Richard says, 'Me got the DVD [title inaudible].' 
Ethan says, 'I got the video game,' and Christopher says, 'And I got big video; it's X Man and Batman, Superman, X Man.' Peter: 'Me got da Superman DVD.' Richard says, 'You know, that be my Nemo DVD.' Christopher says, 'And I got Nemo DVD.' Richard: 'You know, shark, shark him got bite.' Christopher: 'Me a Power Ranger.' Richard picks up one of the airplane parts and Christopher takes it away saying, 'No, no, no.'... Christopher gets up and says, 'And Superman can punch the building.' Richard: 'And Batman can beat the balloon.' Christopher: 'No he can't; he only can punch the car and punch the robot and punch people and punch Peter and punch Ethan, but he can't punch me because I'm stronger!' Ethan: 'And I'm X Man'...Ethan to Christopher: 'I can punch your face.' Christopher: 'No I can punch my brother, cut my brother to pieces, and I can cut you to pieces.' Richard, 'And me can.' Peter: 'Me can do,' he makes a judo stance; 'Teacher I can punch my brother.' Richard, 'And I can punch my Daddy.' Christopher, 'No!' Richard, 'Me can punch my Daddy! Look, look, look me can punch mine Daddy! Yes me can, me can punch my Daddy!' Christopher, 'I'm going to be Batman. I'm going to change into Batman. I have to be the Daddy. I am Batman and I can spray light!'

Here the boys were clearly concerned with relative power. As in the interactions described above, these boys saw power as extreme, aggressive and somewhat arbitrary. Again, I suggest that this comes from the typical experience of children in urban society of being relatively powerless in a world dominated by adults - a condition not experienced to the same extent by rural children who inhabited a world of mixed-age peers. The boys' conversation also reflects the desire of urban kindergarten children to establish their place in a world of equal and unrelated peers. Each wants to establish his power relative to the others. This concern was much less pressing for rural children who were generally in the company of relatives and for whom relative status was ascribed by age. I turn below to urban children's attempts to define their relationship with classmates and the influence of this kind of play on their views of self and society.

\section{Friendship in Urban Kindergartens}

Urban kindergarten children moved from home situations where they were closely monitored by adults to large classes where they had to negotiate their way through a group of unfamiliar peers of equal status. In many kindergartens, children were only loosely supervised by adults and therefore needed to develop strategies to protect themselves from aggressive children, to develop predictable routines and relationships, and to protect these from incursions from other 
children (see also Corsaro 1997). The absence of any clear hierarchy among the children created a situation where children had to come up with strategies to try to control their peers and establish some kind of predictable social order.

Corsaro (2003) demonstrates that Italian and American preschool children establish social order among their peers through friendship routines, and I observed a similar preoccupation with friendship among urban Fijian kindergarten children, who used friendship to define who was in and who was out in particular situations to transform chaos into predictable routines. In more controlled kindergartens, children used friendship to develop some kind of autonomous identity and social structure in situations largely dictated by teachers.

All over Suva, I encountered the ritual of the 'friendship thumb'. One child would extend his or her thumb towards another in friendship, who would respond by pressing it with his or her own thumb to confirm the friendship. Children also tried to establish in-groups through carefully sharing only with select others, even though teachers resisted this, encouraging children to share with everyone. Bonds were also forged through establishing points of similarity. For example, I observed one boy who had joined a kindergarten late in the term frequently pointing out similarities between his lunch, his clothing and so on and those of other children by calling out, 'Eh look, same-same!'

The use of friendship to try to establish social networks was evident during lunch period at one kindergarten. From my notes:

Christopher opens his lunch box revealing pieces of birthday cake neatly wrapped in tin foil. Aaron immediately holds out his hand asking for some. Christopher, takes a piece, breaks it in half, and offers some to Aaron and some to Richard. Ethan and then Aaron reach across the table and offer their thumbs to Richard who presses each in return. Aaron then tells one of the girls, Seini, to offer her thumb to Bessie, another girl sitting across the table, and the two girls press thumbs together. Richard holds up a roti (flatbread) in front of his face like a steering wheel, making car noises and then bites a hole through the middle and looks at the other boys near him giggling. Christopher points to Anil, a two-year-old sitting next to Richard, and says, 'He doesn't like it. He's scared.' But then Christopher picks up his own chicken bone and holds it in front of his eye like a telescope looking first at Anil and then at Richard. Ethan has been watching and offers a friendship thumb to Richard, who accepts, and then to Aaron, who pushes Ethan away and gets up. Ethan grabs Aaron's arm trying to get his thumb, but Aaron pulls away. 
Here, the children manoeuvred quietly at lunch to define who was in and who was out by sharing food, pressing thumbs and engaging in each other's games, while the teacher exhorted them to eat their lunch and not to talk and otherwise socialise. 'This is eating time! NO talking!' Christopher carefully doled out his birthday cake to most of the boys but to only one of the girls, the daughter of a national rugby star and the single girl the boys routinely played with. When the teacher suggested that Christopher give some cake to me and to a girl who had forgotten to bring her lunch that day, he ignored the suggestion, using his cake to define his circle of friends. He also quietly suggested that boys were friends with boys and girls with girls when he suggested that Bessie and Seini press thumbs but did not offer his own thumb to either of them. These friendship routines reduced the chaos potentially present in a large group of children by defining who interacted with whom and what they played - as when Richard and Christopher joined together in using their food as devices to look at other children. These routines are also used to resist the teacher's authority since most teachers insisted that all of the children should be friends, that they should focus on the teacher not on other children, and that mealtime in particular was supposed to be a quiet activity. The children also used offers and rejections of friendship to control their peers, as when Aaron refused Ethan's proffered friendship thumb to express displeasure at some unknown cause.

In more highly structured schools, children's use of friendship to resist too much control by teachers over their lives was particularly apparent. In one such preschool, one of the few occasions when children had any control over their companions was when they chose tables for eating their snacks. In this preschool, the children carefully manipulated table choice to establish friendships. On one occasion, a girl called Emma told another, Lani, not to sit next to her because that chair was for her 'friend'. But when Emma's friend came in and sat somewhere else, Emma called first one boy and then another girl to sit next to her, trying to keep the seat for a friend. Lani, in the meantime, came and told me that her friend was Kenny and went and sat next to him. In this way, children established alliances and a sense of independent identity in a world where the teacher controlled much of what they did.

Children also used friendship to try to control each other. At one preschool, for instance, one of the boys was from Bangladesh and had a British mother. This child, who was clearly not used to local school conventions, routinely interrupted the teachers to tell long stories about Bangladesh and got up and wandered around the room while the other children sat quietly. He also often insisted on being chosen when the teachers were picking out children to do some favoured activity. The children reacted to this behaviour by implicitly refusing to be his friend. One day, when he walked in after retrieving his lunch bag and sat down, all the other children got up and moved to another table. As 
more children filed into the room, they avoided the boy alone at his table and filled up other tables until the teacher came in and told two boys to sit with the Bangladeshi boy.

Corsaro (2003) argues that children use friendship to try to establish control in unfamiliar environments with no clear social structure, and this seemed to be the case in Fijian kindergartens. Friendship among equals, however, is a rather different kind of social principle than the age hierarchies of rural children, all of whom know each other well and whose relationships to each other are clearly defined. When urban children form friendships, they look for those who are similar in some way, often focusing on some principle not particularly important in the adult world. For instance, in one kindergarten, the children routinely compared lunches, hitting upon chance similarities in the colour of juice bottles and so on to form friendships. From my notes, as the children come in with their lunchboxes and chose table companions for lunch:

Tevita sits next to Martin: 'Hey, us two!' Martin: 'Us two! Hey, same-same bag!' (pointing to their lunchboxes). Tevita: 'Us two! Us two Martin!'

Martin, to a third boy, Simon, who enters with his lunch bag: 'Us two, all of us!'

Simon to Martin and Tevita: 'Us two!' At another table, Ana and Sera sit down together and compare their juice bottles: Ana: 'Eh, same-same!'

Sera: 'Eh, same-same!'

In these examples, children establish and cement relationships by finding common ground. Rural children interact mostly as occupants of fixed roles in larger kinship structures. In contrast, urban children interact as autonomous individuals each trying to control his or her own environment. In the process, not surprisingly, they often define their identities in terms of consumption, commenting on clothes, lunchboxes, toys, or, as in the superhero conversation among Christopher and his friends, possession of DVDs and computer games. This suggests a clear shift in children's sense of self, consistent with the preoccupation with autonomy and power evident in much of their play. These children internalise distinctively Fijian assumptions about hierarchy in an experiential world that prompts them to think of themselves as autonomous individuals who must control their world.

\section{Conclusion}

Tuzin was ahead of his time in suggesting that the same cultural beliefs can take on different meanings for people depending on the ways that these beliefs 
impinge upon their experiential world in childhood. Male cult secrets were carefully guarded from women and children among the Ilahita Arapesh, and children were tricked with stories of dangerous and aggressive cult spirits. When children tried to understand their world and contemplate its dangers they told each other fearsome ghost stories that continued to shape their emotional reactions to religious beliefs even after they learned that these stories were lies told to trick women and children. To understand people's conceptions of self, society and culture, one must examine not only the belief system itself but also the ways that it is experienced by children, who are in general distinctively positioned in society and exposed to cultural beliefs and social principles in different ways than are adults.

Tuzin's ideas - similar to models since developed by Corsaro, Tannen, Harris and many others - give us new kinds of insight into contemporary Fiji. Indigenous beliefs about rank and human nature continue to shape the ways that adults treat children at home and at school. But the distinctive social experiences of urban children, particularly in kindergartens, transform the ways that these assumptions are internalised by children so that, I suggest, Fiji's urban children will grow up to think of themselves as autonomous individuals in a larger social hierarchy that is not necessarily god-given but could, in fact, be contested.

\section{Acknowledgments}

I observed children's play in Rakiraki, a village in the north-east of Fiji's main island, Viti Levu, in 1997, 2000 and in 2003 (Brison 1999, 2007). I then observed children in nine Suva kindergartens for periods of two to six weeks each in 2006 and 2007. I chose kindergartens associated with a range of ethnic and religious groups and social classes, some affiliated with schools and others private. Research was funded by two National Science Foundation summer grants and by Union College. I thank Sara Melton and Carly Aimi for helping me with the Suva kindergarten research.

\section{References}

Anderson-Levitt, Kathryn M. (ed.) 2003. Local Meanings, Global Schooling: Anthropology and World Culture Theory. Palgrave Macmillan: New York.

Becker, Anne E. 1995. Body, Self, and Society: The View from Fiji. Philadelphia: University of Pennsylvania Press. 
Brison, Karen J. 1999. Hierarchy in the World of Fijian Children. Ethnology 38:97-119.

Brison, Karen J. 2007. Our Wealth is Loving Each Other: Self and Society in Fiji. Lantham, Md: Lexington Books.

Corsaro, William A. 1997. The Sociology of Childhood. London: Pine Forge Press.

Corsaro, William A. 2003. We're Friends, Right?: Inside Kids' Culture. Washington, DC: Joseph Henry Press.

Harris, Judith Rich 1999. The Nurture Assumption: Why Children Turn Out the Way They Do. New York: Touchstone.

Hirschfeld, Lawrence A. 1988. On Acquiring Social Categories: Cognitive Development and Anthropological Wisdom. Man 23:611-38.

Hirschfeld, Lawrence A. 1990. Acquiring Social Categories. Man 25:146.

Holland, Dorothy, Debra Skinner, William Lachicotte jr and Carole Cain (eds) 1998. Identity and Agency in Cultural Worlds. Cambridge, Mass.: Harvard University Press.

Jones, Gerard 2003. Killing Monsters: Why Children Need Fantasies, Super Heroes and Make-Believe Violence. New York: Basic Books.

Kulick, Don 1997. Language Shift and Cultural Reproduction: Socialization, Self, and Syncretism in a Papua New Guinean Village. Cambridge: Cambridge University Press.

Lanclos, Donna M. 2003. At Play in Belfast: Children's Folklore and Identities in Northern Ireland. Piscataway, NJ: Rutgers University Press.

Mageo, Jeannette Marie 1998. Theorizing Self in Samoa: Emotions, Genders, and Sexualities. Ann Arbor, Mich.: University of Michigan Press.

Martini, Mary 1994. Peer Interactions in Polynesia: A View from the Marquesas. In Jaipaul L. Roopnarine, James Ewald Johnson and Frank H. Hooper (eds) Children's Play in Diverse Cultures, pp. 73-103. Albany, NY: State University of New York.

Mead, Margaret 2001. Coming of Age in Samoa: A Psychological Study of Primitive Youth for Western Civilisation. New York: Harper Perennial Modern Classics.

Morton, Helen 1996. Becoming Tongan: An Ethnography of Childhood. Honolulu: University of Hawai'i Press. 
Ochs, Elinor 1988. Culture and Language Development. Cambridge: Cambridge University Press.

Paley, Vivian Gussin 1986. Boys and Girls: Superheroes in the Doll Corner. Chicago: University of Chicago Press.

Schwartzman, Helen B. 1978. Transformations: The Anthropology of Children's Play. New York: Plenum.

Tannen, Deborah 1990. You Just Don't Understand: Men and Women in Conversation. New York: Morrow.

Toren, Christina 1990. Making Sense of Hierarchy: Cognition as Social Process in Fiji. London: Athlone.

Tuzin, Donald F. 1987. On the Resemblance of Fathers to Their Children: The Roots of Primitivism in Middle-Childhood Enculturation. In L. Bryce Boyer and Simon A. Grolnick (eds) The Psychoanalytic Study of Society. Volume 15: Essays in Honor of Melford E. Spiro, pp. 69-104. Hillsdale, NJ: Analytic Press. 